\title{
Examining Ghana's Cash Transfer Programme Outcomes in the Ejisu-Juaben Municipality from Conversation and Membership Categorisation Analyses Perspectives
}

\author{
Dennis Puorideme \\ Department of Development Studies \\ SDD University of Business and Integrated Development Studies \\ puorideme@gmail.com \\ DOI//http://dx.doi.org/10.4314/gjds.v181.6
}

\begin{abstract}
\end{abstract}
Since the start of cash transfer programmes in developing countries in the late 1990 and its spread, studies have demonstrated a variety of outcomes comprising education, health, and nutrition for the poorest households. These studies focused on macro analysis of programmes' outcomes but paid little attention to an indepth micro study of the everyday intersubjective accounts and actions of local community focal persons and caregivers, which construct programme outcomes. The objective of this study is to highlight the everyday concrete outcomes of a cash transfer programme in Ejisu-Juaben Municipality in Ghana. This study draws on Foucault's notion of subjectivation and discourse to construct a conversation and membership categorisation analyses framework to explore community focal persons' and female caregivers' conversations from focus group discussions. The Livelihood Empowerment against Poverty cash transfer programme in Ghana is the empirical case. This article demonstrates that caregivers and poor households are happier, practice joint decision-making, and have cohesive social relations in poor households. Thus, localised programme outcomes improved participation in the decision-making, happiness, and social cohesion of beneficiary poor households. Evaluation mechanisms for programme outcomes could consider the everyday intersubjective accounts, practices of focal persons, caregivers/beneficiaries in poor households at the micro-level. 
Keywords: Social Protection, Ethnography, Discourse, Subjectivation, Governmentality

\section{INTRODUCTION}

Cash transfers (CT) programmes including Ghana's Livelihood Empowerment Against Poverty (LEAP) outcomes have been studied extensively (Fiszbein \& Schady, 2009; Díaz Langou, 2013; Handa et al., 2014; Carvalho \& Rokicki, 2019) since the unprecedented spread of these programmes in developing countries in the past two decades (Barrientos \& Hulme, 2009; Fiszbein \& Schady, 2009). Like many CT programmes in developing countries, the LEAP cash transfer programme is Ghana government's flagship social protection programme, which provides cash transfers, and recently health insurance, to both urban and rural poor and vulnerable households. Studies covering CT programmes outcomes including "human development outcomes, such as school enrolment and attendance and health services utilisation" (Barrientos, 2014, p. 199), households' consumption, and recently gender relations outcomes have come to the fore (Barber \& Gertler, 2009; Camfield, 2014; de Brauw et al., 2014; Scarlato et al., 2016) at a macro-level. In this way, CT programmes outcomes appear unproblematic essential elements, which deny local community representatives and recipients participating in CTs programmes a little space of agency in constructing programme outcomes intersubjectively. This articles argues that local community representatives and caregivers construct CT programmes outcomes at the intersection of the self and the apparatus of the programme (Foucault, 2010). How do caregivers and community focal persons concretely and intersubjectively construct the LEAP cash transfer programme outcomes in local communities? Adding to the already documented dominant macro level outcomes of these programmes in developing countries, this article highlights the taken-for-granted everyday concrete outcomes of a cash transfer programme in Ejisu-Juaben Municipality in Ghana.

The article is presented in six major sections. First, an introduction and a brief overview of the LEAP CT programme, which describes the conceptual categories of caregivers and community focal persons and the underlying conditions that guarantee eligible poor households' participation in the programme. It presents a review of literature focusing on CT programmes' outcomes in developing countries. The theoretical point of departure is Foucault's notion of subjectivation in relation to the government of self and others (Foucault, 2010), which is an aspect of governmentality (Foucault, 2007). It is an ethnographic-discourse study with 
conversation and membership categorisation analyses framework (Sacks, 1995; Schegloff, 2007a, 2007b). Finally, it presents data analysis and discussion of findings, and conclusion and recommendations.

\section{The LEAP Cash Transfer Programme in Ghana}

The LEAP cash transfer programme is one of the five flagships social protection programmes outlined in the Ghana National Social Protection Policy in 2015 as a social assistance programme. It was established in 2008 out of a National Social Protection Strategy (NSPS) developed in 2007 to coordinate social protection programmes in the country (Government of Ghana, 2015). The LEAP programme receives financial and technical support from transnational agencies including the World Bank, the Department for International Development (DFID), the United States Agency for International Development (USAID) and the United Nations International Children's Emergency Fund (UNICEF) aside the Government of Ghana (World Bank, 2016; Puorideme, 2018). Generally, Ghana's national social protection policy describes the LEAP programme as a cash transfer programme. However, the programme secretariat and participating transnational development partners insist there are soft conditions and co-responsibilities attached to the programme (Puorideme, 2018).

Fundamentally, the programme provides cash grants to poor households with orphans, vulnerable children, people with disabilities and the aged. It promotes access to services to reduce poverty. Poor households are selected by applying the proxy means test (PMT) and community targeting mechanisms, and the specific processes include the identification of poor households by the LEAP community focal persons respectively and the administration of a PMT questionnaire. The LEAP programme is tied to "(soft) conditions or coresponsibilities" (World Bank, 2016, p. 33) comprising school enrolment and attendance and health services utilisation for children between the ages of 5 and 15 years. Thus, a team of social workers at both the LEAP programme secretariat at the national office and the Department of Social Welfare in district offices across the country monitor and enforce the conditions or co-responsibilities (Puorideme, 2018).

In doing so, these officers provide beneficiary households with information brochures that remind the households about the duties and obligations that link them to the programme. The officers access the poor households through the community focal persons and the caregivers. The community focal persons are installed in beneficiary local communities by the programme secretariat as 
intermediaries between the programme and the poor communities in which the poor households are located whilst the caregivers represent the poor households directly (Puorideme, 2018). However, a recent programme performance review shows that the community focal persons are less involved in the activities of the programme (World Bank, 2016). Thus, the programme establishes relations with the poor households in local communities through these categories of persons; that is, the caregivers and community focal persons. Studies including impact assessments about the LEAP CT programme outcomes particularly school enrolment and attendance, and health services utilisation have been extensively reported (Handa et al., 2014; Owusu-Addo, 2016; Roelen et al., 2015). The next section outlines existing relevant studies of CT programme outcomes in developing countries to situate the study.

\section{CASH TRANSFER PROGRAMME OUTCOMES}

Cash transfer programme outcomes in developing countries have been studied extensively. Some of these studies show positive outcomes for women and beneficiary poor households (Scarlato et al., 2016) while other studies have shown the cost of these programmes for women and participating poor households (Molyneux, 2006; Bradshaw, 2008; Bradshaw \& Víquez, 2008). The outcomes of CT programmes are heterogeneous including economic and human capital development with transformative effects (Kabeer \& Waddington, 2015; Molyneux et al., 2016) in developing countries. In this article, I categorise the literature review into two main themes: gender and decision-making, and education and health outcomes in the participating poor households of local communities in developing societies. The categories and subheadings presented below were patterns observed during the literature review process.

\section{Gender and Decision-Making Outcomes}

Studies of CT programme outcomes are moving beyond the narrow focus on economic impacts to include more transformative effects such as gender and decision making power dynamics in participating households (Holmes \& Jones, 2013; Molyneux et al., 2016). By transformative effects, I mean CT programmes are not necessarily tied to quantitative outcomes, for instance income indicators or statistics and market logic (Puorideme, 2018). Studies including Radel et al. (2017) suggest that CT programmes have some transformative, yet marginal outcomes. In an analysis of a household survey of Oportunidades in Mexico, one of the largest CT programmes, Radel et al. (2017) report a persistent gender gap in decision- 
making. However, they noted that the programme created opportunities for women to access land tenure rights in some communities. Thus, Radel et al. (2017) pointed out that the Oportunidades programme proved beneficial in many ways that are unrelated to its design, and the conditions and actions it require of women participants.

A similar study of Brazil's Bolsa Família CCT programme reported "significant impact on women's decision making, but with heterogeneity in effects" de Brauw et al., 2014, p. 487 in both urban and rural poor households, and that the programme gives women a voice in urban households decisions. According to de Brauw et al. 2014, the programme raised women's decision making power about contraception, school attendance and health expenditure in urban poor households, but they noted that women's decision making power reduced in rural households. However, in a disclaimer statement, they emphasised that their "measures of women's decision-making power refer to a woman's subjective assessment of her own decision-making role in several general spheres of households decisions and are therefore subject to reporting bias" (de Brauw et al., 2014, p. 497). There is need for novel methodological and analytical frameworks to investigate the everyday concrete and intersubjective actions of the CT programmes' recipients in local communities and how they construct programme outcomes.

\section{Education and Health Outcomes}

A study of thirteen CT programmes in Latin America demonstrated that they "have been effective in increasing the use of preventive services" (Ranganathan \& Lagarde, 2012, p 95), and serve as conduits to poor households' access to health care and utilisation services yet these outcomes are difficult to sustain. In Mexico, "the Oportunidades conditional cash transfer programme is associated with better quality of prenatal care for low-income, rural women" (Barber \& Gertler, 2009, p. 24) by encouraging the utilisation of health care services in rural communities. Similarly, a study of the LEAP CT programme outcomes in poor households in Ghana suggests the programme improves access to health care and nutrition and education, and in doing so, it does "improve both material and non-material aspects of wellbeing" (Owusu-Addo, 2016; Roelen et al., 2015, p. 63). In addition, the heads of poor households participating in the LEAP CT programme are happier (Handa et al., 2014). Studies of Chile Solidario and Bolsa Família in Chile and Brazil respectively revealed CT programme outcomes are positive for school enrolment and attendance and access to health care (Barrientos et al., 2016; Martorano \& Sanfilippo, 2012). 
However, like many social protection programme instruments in developing countries, CT programmes "present special challenges to evaluating impact" (Davis et al., 2012, p. 1) such that their outcomes are "complex and context-specific" (Camfield, 2014, p. 107). The studies discussed above do not account for the "hows" of these studies and CT programmes outcomes in particular (Stokoe, 2012, p. 345). By this, I mean the ways in which local community representatives, including community focal persons and caregivers, construct CT programme outcomes are least accounted for in these studies. Concerning challenges and complexities associated with these programme outcomes; this article sheds light on the everyday concrete intersubjective actions and practices of local community representatives, which construct CT programme outcomes in developing countries. It does so by relying on novel theoretical and methodological perspectives in studies of discourse and governmentality, which attend to the micro-ethnographic details of the practices of community focal persons and caregivers of poor households in local communities in relation to the LEAP CT programme. The next two sections present the specific theory, methodological and analytical framework of this study.

\section{THEORETICAL FRAMEWORK}

The article discusses the "government of self and government of others" (Foucault, 2010, p. 6) in terms of the conduct of conduct (Foucault, 2007) with focus on the notions of subjectivation(Foucault, 2005, 2010) at the intersection of subjectivity and truth (Foucault, 2017) to explore how community level representatives and recipients construct CT programme outcomes. It is important to state here that the government of self and government of others is enmeshed fundamentally in Foucault's notion of governmentality - conduct of conduct (Foucault, 2007). Within Governmentality, "techniques and practices addressed to individual human subjects within particular, local institutions could also be addressed to techniques and practices for governing populations of subjects at the level of a political sovereignty over an entire society" (Gordon, 1991, p. 4). Thus, governmentality is an art of government that employs forms of knowledge and power to shape the conduct of populations and individuals in certain societies through a process of subjectivation.

The concept of subjectivation occurs at the intersection of an apparatus of power (truth) and the practices of the self (subjectivity) in which the subjects' practices of 'truth' enables them to become the subjects of true discourses. The subjects constitute themselves in true discourses without totally submitting themselves 
to the law; thus, they are bond to the truth but not the law (Foucault, 2005). The practice of the self is meant to "support and ensure the constitution of oneself as a moral subject" (Davidson, 2005, p. xix) such that "the enunciation of the truth arises from the subject's own practices of freedom" (Milchman \& Rosenberg, 2009, p. 70). The practices of self can be understood as follows:

It is the form of relationship that one decides to have to things, the way in which one places oneself in relation to them, the way in which one finalises them in relation to oneself. It is again the way in which one inserts one's own freedom, one's own ends, one's own project in these things themselves, the way in which one as it were puts them in perspective and uses them. (Foucault, 2017, p. 253).

Thus, subjectivation "unfold as the government of the self intersects with the government of the other" (Bang Lindegaard, 2016, p. 99) in terms of the intersection of the practices of self and the apparatus. The unfolding practices of subjectivation enhances a more in-depth understanding of knowing "the truth of the subject" and "the situation of the truth of the subject" (Foucault, 2017, p. 49). By this, I mean grasping the concrete accounts, actions and practices of the subjects in their own interest at the intersection of discourses and power (Puorideme, 2018).

\section{METHODOLOGY}

This article is an ethnographic-discourse study (Oberhuber \& Krzyżanowski, 2008), which "attends to the micro-ethnographic detail of actual practices, procedures and technologies of governance" (Mcllvenny, 2016, p. 265) in relation to the LEAP CT programme. This study is a Foucault-based analysis that combines the features of governmentality studies, ethnography, and discourse studies approaches - conversation analysis (CA) and membership categorisation analysis (MCA) - to investigate the micro-ethnographic actions and practices of community focal persons and caregivers in relation to the LEAP CT programme practice. Thus, the analysis focuses on localised talk-in-interactions and intersubjective accomplishments of community focal persons and caregivers.

The data for this article is part of data that was collected from May 2017 to August 2017 in Ghana for a Ph.D. studies. Thus, the data was collected from two focus groups in a local community in the Ashanti region of Ghana. The two groups comprised eight community focal persons (two females and six males) and eight female caregivers. The focal persons are relays of power within the programme while the 
caregivers are representatives of eligible poor households in the local community (Puorideme, 2018). The selection of community focal persons was tied to their active participation in the translation of the programme at the community level as well as their membership in the communities they individually represent. Thus, only two female focal persons were active at the time of the data collection, so they were included in the group. On the other hand, the selection of eight caregivers was tied to their availability and willingness to participate in the focus group discussions. Generally, the numbers of participants in each of these groups were limited to eight individuals for efficient group management and quality discussion.

The transcript excerpts presented in this study emerged from conversation from these two groups of participants. The data included talk, actions and accounts of practices. The focus group discussions were conduct in the local language, the participants spoke Asante-Twi, and were recorded using audio-visual devices and transcribed with the CA mind-set (Hutchby \& Wooffitt, 2008). By CA mindset, I refer to detail transcription of talk-in-interaction as is recorded to bring out relevant conversational features for analysis. Thus, the researcher as a participant of each of the two groups introduces topics and facilitates the discussions by allowing participants to relax and interact without imposing constraints. In this way, an interview guide is less relevant with the ethnographic-discourse analytic perspective. Participants' utterances were transcribed in the local language, but without glosses, and then translated into English languages for analysis; thus, using a two-line transcription approach, the local language is transcribed in the first line and the pragmatic English translation beneath it (Puorideme, 2018).

Analytically, the article engages conversation analysis (CA) and membership categorisation analysis (MCA) features (Sacks, 1995; Schegloff, 2007a, 2007b) to investigate the sequential organisation of conversation or talk and the categorical practices "by which subjectivation is morally accomplished in social interaction" (Mcllvenny, 2016, p. 265). The article also investigates ways community focal persons and the caregivers themselves construct the LEAP programme outcomes. From ethnomethodologically inspired CA and MCA analytical perspectives, the sequential organisation of talk-in-interaction and the categorical practices of community focal persons and caregivers "take their shape reflexively and indexically according to the context in which they are produced" (Stokoe, 2012, p. 352). In this article, context encompasses the situated context of interaction as participants of the programme and the socio-political context of the community in which the participants are members (Reisigl \& Wodak, 2016). 


\section{DATA ANALYSIS}

The analysis section makes visible the actions, practices and accounts of caregivers and community focal persons within the LEAP CT programme apparatus (Foucault, 2017) where the community focal persons and the caregivers themselves construct programme outcomes at the intersection of the government of the self and the practices of the programme (Foucault, 2010). The analysis focuses on two aspects of outcomes. First, changes in the members of poor households in the local community; second, changes in caregivers' self-practices and actions in poor households. Hence, the following sections comprise an analysis of accounts, actions, and practices of community focal persons and female caregivers.

\section{Focal Persons' Accounts of Changes in a Local community}

This section focuses on analysing the LEAP CT programme outcome at the intersection of the categorical practices and accounts of community focal persons and the practices of the programme in the local communities. The transcript below is an excerpt of a focus group discussion with community focal persons in a local community in Ejisu-Juaben municipality. The focus group comprised two female focal persons (FFP1 and FFP2), and six male focal persons (MFP1, MFP2, MFP $3, \mathrm{MFP}_{4}$, MFP5 and MFP6). Thus, FFP stands for female focal person while MFP stands of male focal person. The selection criteria of the participants in the discussion are explained in the methodology section above. In this transcript excerpt, the participants are responding to a question the researcher $(\mathrm{R})$ asked regarding their experiences as community focal persons (CFPs) in their respective local communities in the domain of the LEAP CT programme.

\section{Transcript excerpt 1:}

1 MFP5: na wo se wobEba

so they said they would come

2 na wDn a betuawつn nso ka and they come and pay them

$3 \quad \varepsilon h \supset$ de $\varepsilon$ na anigye $\varepsilon$ a ba then there is happiness

4 MFP1: hehehehe 
5 MFP5: $\quad$ sEbi obi a nasEbionni bi koraa no

indeed someone who had nothing

6

गnyaa bi bつneho

she/he got something for herself/himself

$7 \mathrm{R}: \quad \mathrm{mm}$

8 MFP5: $\quad$ wวn a sEbi wวn a y\&faa wつn no

those that they selected

9 wDnya bi kakrakraEde yEadwuma

they got something small to work with

10 MFP1: mepa wo kyEw baako wo ha

please there is one here

$11 \mathrm{R}: \quad$ aha $=$ ok

12 MFP6: [((Dma ne nsa so na DrehweR $)$ ]

((he raises his hand and looks at $R)$ )

13

[mepa wo kywe ]

please

14

(1.04)((MFP6 narrates how he worked with officials))

15 MFP6: biribiara ni a na JfrE

she calls if there is anything

16

JfrEsaa:: kJpemmsE

she calls until

17

nyankopon nso tumi baa mu Ewiee asomdwoeहmu

god's willing everything ends peacefully

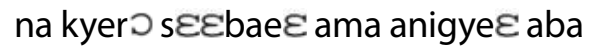


so it came and there is happiness

wotumi hunus $\varepsilon$ seesei nso [nsesesae $\varepsilon$ aba ]

you can see now that there are changes

$[(($ Db० ne tiri nko)) $]$

((nodding))

\{especially orphans\} a na wDw.hD

especially the orphans that are there

a first wDkD sukuu koraa wotumi hunu

at first when they attend school you could see

$s \varepsilon_{\uparrow}$ onipa no ne ho ne ade $\varepsilon_{\text {no }}$

that somethings about the person=

24 FFP1: $\quad \mathrm{mm}$

25 MFP6: $\quad$ na $\uparrow$ Enk $\supset$ yie(.) $\{b u t\} \varepsilon n n \varepsilon$ no

were not going well(.)but today

26

me ankasa m'anitua mu s $\varepsilon$

i myself can see that

27

nne $\varepsilon$ mabebree asesa(.)nanso nso $\supset k \supset$ so

many things have changed(.)and go on

Apart from the sequential and interactional exchanges between the community focal persons (CFPs) in the transcript above, we observe the presence of other categories of persons, for example: "they", "them" and "she" in lines 1, 2 and 15 respectively. The CFPs used these pronouns to qualify and draw in other voices and categories of persons in the ongoing interaction (Reisigl \& Wodak, 2016), for example, the programme officers, the caregivers and the district focal person respectively to enact power relations in the domain of the programme (Foucault, 1980). Enacting power relation between these categories of persons is important for constructing the programme outcomes to the extent that actions and practices in the domain of the programme connect to these categories of persons (Sacks, 
1995; Schegloff, 2007a). For instance, it is interesting to observe the way the CFPs construct the "happiness" (lines 3 and 18) of caregivers and poor households as an outcome, which links the actions and practices of the programme officers and the district focal person in lines 2 and 15 . The happiness of caregivers does appear to be a practice of subjectivation (Foucault, 2005, 2010). By this, it mean the happiness of the caregivers and poor households is bound to the apparatus of the programme the practices of the community focal persons and the district social welfare officers - in which these caregivers constitute themselves as moral subjects of the LEAP CT programme.

At the intersection of self and programme apparatus, the utterances of MFP6 "I myself can see that many things have changed" (lines 26 and 27) appear to reinforce the "happiness" of the caregivers and poor households, which he witnesses and experiences as a member of the local community. In this way, MFP6 is not just expressing commitment to his experiences about the changes in the community rather his commitment to the actuality of the changes demonstrates that the caregivers and the members of poor households receiving the cash grants in the community are doing being governable subjects at the intersection of self and the programme apparatus (Bang Lindegaard, 2016; Foucault, 2005). Thus, the programme is making caregivers and members of poor households happier. For example, these changes are visible in the actions of caregivers in the accounts of MFP6 (line 19) as "they got something small to work with" (line 9), and "the orphans" under their care now "attend school" (lines 21 and 22). The accounts of MFP5 suggest the caregivers of poor households are working, and the orphans attending school as a condition for participating in the LEAP CT programme is a subjectivation practice (Foucault, 2005). According to the community focal persons' accounts in the transcript excerpt and the analysis above, we can say the caregivers are not mere recipients of the cash grant, but they actively constitute themselves as moral subjects at the intersection of the apparatus of the programme. In addition, the CFPs construct communal happiness as the programme outcome tied to their experiences and observations of the everyday actions of beneficiary poor households within the domain of the programme.

\section{Focal Persons' Account of Changes in Caregivers' Decision-Making Practices}

The focus of this section is to explore CFPs' accounts of caregivers' decision-making practices at the intersection of the LEAP CT programme. The transcript excerpt is a continuation of the conversation between the MFPs and FFPs in the focus 
group mentioned above but it focuses on caregivers' decision-making aspect. In this excerpt, they are responding to a question the researcher (R) asked about the social relations and practices of members of the poor households receiving the cash grants, and the actions and practices of men (husbands) women (wives) in particular. The CFPs' conversation account is presented in the transcript and analysed below.

\section{Transcript excerpt 2:}

1 FFP1: $\{$ sister $\}$ baako tebEn me a sister lives close to me

2 Sno=w yi maame no w. n a yi ne kunu they selected the mother not the husband

3 w.w. they have two children that attend school

4 (0.12)((FFP1 narrates deferring payment))

5 R: $\mathrm{mm}$

6 FFP1: nti Dne ne kunu no nyina:: wDnnye so she and the husband they don't take it

7 nti sEDreba a so when she is coming

8 Jne ne kunu no na woba she comes with the husband

9 nti yei $=a=w \supset$ se wDn mfa nto hD so this they say they should keep it

10 na se w.ma kwan na w. be bue sukuu a if school vacates and reopens

11 na wつn akつgye 
then they go and take

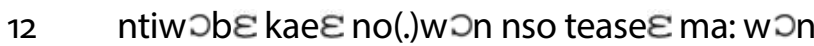

so when they said it(.)they understood them

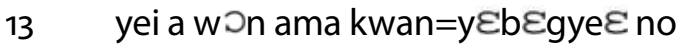

as school vacates and we about to receive it

14 गnnye(.)fofor $\supset$ no a yE sane bEgye no

she won't take it(.) unless the next payment

15 a wวbe bue sukuu no(.)w ogye a

when they reopen school then they take it

16 na wगn a dane a ma ne ban o(.)na ne ba no de kJ

and gives it to the child for school

17 nti Ey ntiase $\varepsilon$ ma

so that is the understanding

18 Jne ne kunu no

between her and the husband

19 Ewगmu sE barima no na गtwere $\varepsilon$ nanso

even though the man registered for the cash but

20 Jbaa no din na Ebae

the woman's name was captured

21 ntiobaa no nso nim sE

so the woman also knows that

22 Jne ne kunu nyinaa na wEn mma ne nk Jdaa no

the children belong to both of them

23 nti wogye=a na $=$ गde $=$ na $=$ kyerEs $\varepsilon$ 
so they take it for the child so that

24

wDn ho a henhanne w.hP

their burden reduces in regard to education

25 ahaa

that is it

In the accounts of the CFPs, we observe in lines 3 and 15 to 18 , female caregivers jointly making decisions with their spouses (husbands) in their own mutual interest by inserting their own "freedom", "ends" "project" (Foucault, 2017: 49) in the apparatus of the LEAP cash transfer programme. It is important to point out that the joint decision-making practice is accomplished within the category device of family (Sacks, 1995) comprising "mother", "husband" and "children" (lines 2 and 3) with sequentially organised category bound relations and practices (Schegloff, 2007b) as we observe in lines 3 and 8 . Thus, the accounts of the community focal persons in the transcript above demonstrate concrete decision-making practices of the caregivers of poor households as fundamental practices of freedom (Foucault, 1997) and cohesive social relations as LEAP CT programme outcomes. By this, I mean the ways in which the caregivers constitute themselves and act in their own interest.

As the practices of self (Foucault, 1997) intersects with the apparatus of the programme (Foucault, 2005, 2010), we observe an account of moral and practical accomplishment between female caregivers and their spouse and the programme officers; "so when they said it (.) they understood them" (line 12). In this context, FFP1 uses "they" to refer to the female caregiver and her husband, and the programme officers in the latter part of her statement. In that regard caregivers' moral and practical accomplishment and joint decision-making practices are negotiated programme outcomes, which we cannot observe at an abstract level or through a programmatic evaluation machine (Puorideme, 2018). In the accounts of the community focal persons, the caregivers of programme households concretely design and insert their own projects in the apparatus of the programme in their own interest as can be observed from lines 13 to 16 in the transcript above. It can be seen from the focal person's accounts that the ultimate project of the caregiver is "the understanding between her and the husband" (lines 17 and 18), which is not absolutely conditioned by the LEAP CT programme apparatus (Foucault, 2017), but a reflective relationship caregivers have about themselves in relation to the programme. In this way, the voices of women in decision making at the household 
level are heard. In the next section, I investigate the practices of caregivers in doing being accountable subjects as a practical accomplishment at the intersection of the LEAP CT programme apparatus.

"I let the man know": Constructing Cohesive Social Relations in Poor Households

The transcript excerpt presented and analysed below is a conversation from a focus group comprising eight participants who are female caregivers of poor households. In the transcript below, the female caregivers are responding to questions the researcher ( $R$ ) asked about the social relations and practices of men (husbands) and women (wives) and between them at the intersection of the LEAP CT programme in the poor households.

\section{Transcript excerpt 3:}

$1 \mathrm{R}$ : mokunu pene so mamo begye de $\varepsilon=$ do your husbands allow you receive it

2 FC7: [aane

yes

3 FC8: [aane

yes

$4 \mathrm{R}: \quad=$ anaa s $\varepsilon$ mogye a mo nka nkyer $\varepsilon$ wDn

or you don't tell them about it

5 FC7: yع ka pa ara

indeed we tell them

$6 \mathrm{R}$ : abusuapanin no nso pene so de $\varepsilon$

does the family head agree you take it

7 FC8: aane $=$ oh adEn

yes of coures

8 FC7: yei boa kakra na yei nso boa kakra 
this one helps a little and that one also helps a little

9 (0.40)((FC7 narrates how she manages the cash))

10 FC7: nti Eba bi ara(.)me ma barima no hunu s $\varepsilon$

so when it comes(.) i let the man know that

11 saa sika yei a merekつ gye no

this money that $i$ am going to receive

12 R: uhu

13 FC7: Dnno na Eboa me nkakra kakra

it helps me a little

14 nti Ono nso nya bi a

so when he also gets some

15 na Dde a s. me so

he adds it to mine

$16 \quad \mathrm{R}: \mathrm{mm}$

$17 \quad \mathrm{FC}$ :[Eboa(.)mm]

it helps(.)mm

$18 \quad[((\supset b \supset$ ne tiri nko) $)]$

((nodding)) 
In the transcript above, it is observe that the practices of self (Foucault, 1997) as a practical moral accomplishment in the accounts of female caregivers at the intersection of the moral values of families (Puorideme, 2018) and the practices of the LEAP CT programme (Foucault, 2010, 2017). For instance, the categorical practice of female caregivers: "indeed we tell them" (line 5 ) is morally and practically accomplished at the intersection of the category device of family (Sacks, 1995), and the programme apparatus, which requires the cash grants is used to the benefit of the entire poor household. The "we" (female caregivers) and "them" (husbands) relations is not neutral, but a binding moral relation between husbands and wives in the poor households of Ghana's local communities. In addition, the female caregivers are doing being accountable to their households as a self-reflective practice within the family and the LEAP CT programme, which are social domains of power (Mcllvenny et al., 2016). In doing so, FC7 constructs accountable gendered subjects (lines 10 and 5 ) as a practical accomplishment in which caring for the members of the household is a shared responsibility between the men and the women (line 8) is an outcome of the LEAP CT programme. By accountable gendered subjects, I refer to the practice in which the female caregivers of poor households constitute themselves and their male counterparts as morally accountable to their households at the intersection of the LEAP CT programme. Thus, the account and practices of the female caregivers (lines 11 and 15) build socially cohesive relations between men and women in poor households at the intersection of self, culture, and the programme. In addition, both female caregivers and their husbands jointly mobilised resources (lines 14 and 15) as accountable gendered subjects by inserting their own freedom and ends into the domain of the programme (Foucault, 2017). In the following sections, this article discusses the findings of this study and presents its conclusion.

\section{DISCUSSION OF FINDINGS}

The data analysis section demonstrates that the community focal persons (CFPs) and the caregivers of the LEAP CT programme concretely construct programme 
outcomes at the intersection of everyday actions and practices of self and the LEAP CT programme as it extends itself into the local communities beyond the core regions of national government (Puorideme, 2018). This study demonstrates three key findings. First, caregivers and the members of poor households are happier. Second, caregivers practice joint decision-making and make women's voices heard in poor households. Third female caregivers' actions give rise to cohesive social relations and joint mobilisation of financial resources in poor households. These findings are systematically presented and discussed in this section.

The "happiness" of caregivers and poor households participating in CT programmes in developing societies is an important outcome and shows a reduction in poverty and human sufferings. However, very few studies except for Handa et al. (2014) directly demonstrate the happiness of caregivers and poor households within these programmes as an outcome. Indirectly, other studies have taken for granted the fact that improved wellbeing through access to education and health services utilisation would lead to the happiness of caregivers and poor households participating in CT programmes in local communities (Roelen, Chettri \& Delap, 2015; Barrientos, Debowicz \& Woolard, 2016; Owusu-Addo, 2016) even though CT programmes outcomes are "complex and context-specific" (Camfield, 2014, p. 107). Aside the methods implemented in these studies, discourse studies methods that pay attention to localised accounts, actions and practices of community representatives do shed light on the happiness of caregivers and poor households in CT programmes as observed in the analysis above. Thus, the happiness of caregivers and poor households is accomplished and sustained in the everyday actions and practices of local community representatives and the programme officers including the district focal person, in the case of the LEAP CT programme in Ghana.

Recently, studies have shown interest in the transformative outcomes of CT programmes in developing societies (Holmes \& Jones, 2013; Molyneux et al., 2016) even though some studies suggest these outcomes are currently marginal and conclude that gaps in gendered decision-making persist (Radel et al., 2017). In this way, attempts by the recipients of the programme to define their own interest through their own everyday actions and practices in the domain of the programme are reported as unrelated to the design and conditions of the CT programmes apparatuses (Radel et al., 2017). However, the nuances of the transformative 
outcomes of $\mathrm{CT}$ programmes in developing societies demonstrate the practical accomplishments of recipients in poor households in local communities in relation to the programme. For instance, this study demonstrates that the caregivers of poor households, in the context of the LEAP CT programme, in the local communities are concretely constituting their own freedom in their own interest through their own everyday actions and practices at the intersection of self and the LEAP CT programme apparatus.

Contrary to the findings of studies such as de Brauw et al. (2014) that there is reduction in women's decision-making power in rural households, this study demonstrates the visibility of women's voices in joint decision-making between women and men, particularly, wives and husbands in their own interests. The audible voices of women are a positive and transformative outcome (Molyneux et al., 2016; Scarlato et al., 2016) that mobilises women's agency to improve the material and social wellbeing of poor household members (de Brauw et al., 2014). In this way, women's decision-making power, a positive outcome of CT programme in developing societies is practically accomplished as a self-reflective practice. By this, I mean women's decision-making power is not an essence like the physical cash, which CT programmes offer women, rather it is accomplished in the everyday actions and practices of the women or female caregivers themselves in the case of the LEAP CT programme in Ghana.

In addition to the practical accomplishment of women's joint decision-making actions and practices in poor households in the domain of CT programmes, this study demonstrates that the actions and practices of female caregivers construct cohesive social relations in poor households and enables joint mobilisation of financial resources. This finding suggests that female caregivers in poor households are not simply recipients of the cash grants, but they are self-reflective to the extent that they refer their actions and practices to the moral values of the family in the local community and the LEAP CT programme apparatus. 


\section{CONCLUSION AND RECOMMENDATION}

Cash transfer programmes have emerged in developing countries as primary instruments of governments' social and development policies and programmes for governing poor households in poor local communities, and a considerable volume of studies focus on investigating the macro-level programmes' outcomes in relation to the rationalities of state governments. In doing so, studies in this field take for granted the everyday micro-level concrete actions and practices of local community representatives, poor households' caregivers and the programme officials, which appear to shape CT programme outcomes in many different ways.

The discussion of the findings presented above have three key implications worth highlighting below. First, cash transfer programmes engender intrahousehold cohesion and have a greater potential of spill over effects into the larger community. Second, cash transfer programmes create space for agency for women caregivers thereby reducing unequal gender power relations in poor households and local communities. Third, providing cash transfers to poor households in poor local communities go beyond income poverty reduction, thus incorporating qualitative methodologies and methods into cash transfer programme evaluations designs or mechanisms reveal micro-level socio-political outcomes that are often missing in quantitative evaluation apparatuses.

Consequently, the findings and implications presented above are more in-depth and innovative, and provide better understanding of localised CT programme practices, which macro-level analysis and grand programmatic evaluations machines take for granted and trivialise. However, this study is unable to account for the actions and practices of male caregivers in local communities participating in the LEAP CT programme, and the findings may be specific to Ghana's context. Thus, future studies in relations to limits of this study in other developing countries' context is needed for a wider perspective and understanding of the findings as presented and discussed.

\section{REFERENCES}

Bang Lindegaard, L. (2016). The discursive intersection of the government of others and the government of self in the face of climate change. In P. Mcllvenny, J. Z. Klausen \& L. B. Lindegaard (Eds.), Studies of discourse and governmentality: New perspectives and methods (pp. 95-118). John Benjamins Publishing. 
Barber, S. L., \& Gertler, P. J. (2009). Empowering women to obtain high quality care: Evidence from an evaluation of Mexico's conditional cash transfer programme. Health Policy and Planning, 24(1), 18-25. https://doi.org/10.1093/heapol/czno39

Barrientos, A. (2014). Social Protection. In B. Currie-Alder, R. Kanbur, D. M. Malone \& R. Medhora (Eds.), International development: Ideas, experience, and prospects (pp. 188-203). Oxford University Press.

Barrientos, A., Debowicz, D. \& Woolard, I. (2016). Heterogeneity in Bolsa Família outcomes. The Quarterly Review of Economics and Finance, 62, 33-40. https:// doi.org/10.1016/j.qref.2016.07.008

Barrientos, A., \& Hulme, D. (2009). Social protection for the poor and poorest in developing countries: Reflections on a quiet revolution: Commentary. Oxford Development Studies, 37(4), 439-456. https://doi. org/10.1080/13600810903305257

Bradshaw, S. (2008). From structural adjustment to social adjustment: A gendered analysis of conditional cash transfer programmes in Mexico and Nicaragua. Global Social Policy, 8(2), 188-207. https://doi.org/10.1177/1468018108090638

Bradshaw, S., \& Víquez, A. Q. (2008). Women beneficiaries or women bearing the cost? A gendered analysis of the Red de Protección Social in Nicaragua. Development and Change, 39(5), 823-844. https://doi.org/10.1111/j.1467-7660.2008.00507.x

Camfield, L. (2014). Growing up in Ethiopia and Andhra Pradesh: The impact of social protection schemes on girls' roles and responsibilities. 9(1), 107-123. https:// doi.org/10.1057/ejdr.2013.36

Carvalho, N., \& Rokicki, S. (2019). The impact of India's Janani Suraksha Yojana conditional cash transfer programme: A replication study. The Journal of Development Studies, 55(5), 989-1006. https://doi.org/10.1080/00220388.201 8.1506578

Davidson, A. I. (2005). Introduction. In F. Gros (Ed.), The hermeneutics of the subject: Lectures at the Collège de France, 1981-1982 (1st ed., pp. xix-xxx). PalgraveMacmillan.

Davis, B., Gaarder, M., Handa, S., \& Yablonski, J. (2012). Evaluating the impact of cash transfer programmes in sub-Saharan Africa: An introduction to the special issue. Journal of Development Effectiveness, 4(1), 1-8. https://doi.org/10.1080 $/ 19439342.2012 .659024$

de Brauw, A., Gilligan, D. O., Hoddinott, J., \& Roy, S. (2014). The impact of Bolsa Família on women's decision-making power. World Development, 59, 487-504. http:// dx.doi.org/10.1016/j.worlddev.2013.02.003 
Díaz Langou, G. (2013). Validating one of the world's largest conditional cash transfer programmes. A case study on how an impact evaluation of Brazil's Bolsa Família Programme helped silence its critics and improve policy. Journal of Development Effectiveness, 5(4), 430-446. https://doi.org/10.1080/19439342.2 013.861501

Fiszbein, A., \& Schady, N. (2009). Conditional cash transfers : reducing present and future poverty. World Bank, Policy Research Report.

Foucault, M. (1980). Power/Knowledge: Selected interviews and other writings 19721977 (C. Gordon, Eed.). Pantheon Books.

Foucault, M. (1997). Ethics: Subjectivity and truth (P. Rabinow, Eed.); Vol. 1). The New Press.

Foucault, M. (2005). The hermeneutics of the subject : Lectures at the Collège de France, 1981-82 (F. Gros, Eed.); 1st ed.). PalgraveMacmillan.

Foucault, M. (2007). Security, territory, population : Lectures at the Collège de France, 1977-78 (M. Senellart, Eed.). Palgrave Macmillan.

Foucault, M. (2010). The Government of self and others: Lectures at the Collège de France 1982-1983 (A. I. Davidson, Eed.). Palgrave Macmillan.

Foucault, M. (2017). Subjectivity and truth : Lectures at the College de France, 19801981 (Frédéric Gros, Eed.). Palgrave Macmillan.

Gordon, C. (1991). Governmental rationality: An introduction. In G. Burchell, C. Gordon \&P. Miller (Eds.), The Foucault effect : Studies in governmental nationality: With two lectures by and an interview with Michel Foucault (pp. 1-51). Harvester Wheatsheaf.

Government of Ghana. (2015). Ghana national social protection policy (p. 63). http:// mogcsp.gov.gh/mdocs-posts/ghana-national-social-protection-policy/

Handa, S., Park, M., Darko, R. O., Osei-Akoto, I., Davis, B., \& Daidone, S. (2014). Livelihood Empowerment Against Poverty Program Impact Evaluation. University of North Carolina, Chapel Hill, NC USA.

Holmes, R., \& Jones, N. (2013). Gender and social protection in the developing world : Beyond mothers and safety nets. Zed Books.

Hutchby, I., \& Wooffitt, R. (2008). Conversation analysis (2nd ed.). Polity.

Kabeer, N., \& Waddington, H. (2015). Economic impacts of conditional cash transfer programmes: A systematic review and meta-analysis. Journal of Development Effectiveness, 7(3), 290-303. https://doi.org/10.1080/19439342.2015.1068833 
Ghana Journal of Development Studies, Vol. 18 (1)

Martorano, B., \& Sanfilippo, M. (2012). Innovative features in poverty reduction programmes: an impact evaluation of Chile Solidario on households and children. Journal of International Development, 24(8), 1030-1041. https://doi. org/10.1002/jid.2873

Mcllvenny, P. (2016). Governmentality, counter-conduct and prefigurative demonstrations: Interactional and categorial practices in the strange case of the United Nathans weapons inspectors. In P. Mcllvenny, J. Z. Klausen, \& L. B. Lindegaard (Eds.), Studies of discourse and governmentality : New perspectives and methodsew perspectives and methods (pp. 265-293). John Benjamins Publishing Company.

Mcllvenny, P., Zhukova Klausen, J., \& Bang Lindegaard, L. (Eds.). (2016). New perspectives on discourse and governmentality. In Studies of discourse and governmentality: New perspectives and methods (Vol. 66, pp. 1-69). John Benjamins Publishing Company.

Milchman, A., \& Rosenberg, A. (2009). The Final Foucault: Government of others and government of the Self. In S. Binkley \& J. Capetillo (Eds.), A Foucault for the 21st Century : Governmentality, biopolitics and discipline in the new millennium (pp. 62-71). Cambridge Scholars Publishing.

Molyneux, M. (2006). Mothers at the service of the new poverty agenda: Progresa/ Oportunidades, Mexico's conditional transfer programme. Social Policy and Administration, 40(4), 425-449. https://doi.org/10.1111/j.1467-9515.2006.00497.x

Molyneux, M., Jones, W. N., \& Samuels, F. (2016). Can cash transfer programmes have 'transformative' effects? The Journal of Development Studies, 52(8), 1087-1098. https://doi.org/10.1080/00220388.2015.1134781

Oberhuber, F., \& Krzyżanowski, M. (2008). Discourse analysis and ethnography. In R. Wodak \& M. Krzyżanowski (Eds.), Qualitative discourse analysis in the social sciences (pp. 182-203). Palgrave Macmillan.

Owusu-Addo, E. (2016). Perceived impact of Ghana's conditional cash transfer on child health. Health Promotion International, 31(1), 33-43. https://doi.org/10.1093/ heapro/dauo69

Puorideme, D. (2018). Social protection and gender at the intersection of discourses and governmentality: A critical ethnographic study of the LEAP cash transfer programme in Ghana. [Doctoral dissertation, Aalborg University]. Aalborg University Press. https://vbn.aau.dk/en/publications/social-protection-andgender-at-the-intersection-of-discourses-an

Radel, C., Schmook, B., Haenn, N., \& Green, L. (2017). The gender dynamics of conditional cash transfers and smallholder farming in Calakmul, Mexico. Women's Studies International Forum, 65, 17-27. https://doi.org/10.1016/j.wsif.2016.06.004 
Ghana Journal of Development Studies, Vol. 18 (1)

Ranganathan, M., \& Lagarde, M. (2012). Promoting healthy behaviours and improving health outcomes in low and middle income countries: A review of the impact of conditional cash transfer programmes. Preventive Medicine, 55 Suppl(SUPPL.), S95-S105. https://doi.org/10.1016/j.ypmed.2011.11.015

Reisigl, M., \& Wodak, R. (2016). The discourse-historical approach (DHA). In R. Wodak \& M. Meyer (Eds.), Methods of critical discourse studies (3rd ed., pp. 23-61). SAGE.

Roelen, K., Chettri, H. K., \& Delap, E. (2015). Little cash to large households: Cash transfers and children's care in disadvantaged families in Ghana. International Social Security Review, 68(2), 63-83. https://doi.org/10.1111/issr.12064

Sacks, H. (1995). Lectures on conversation: Volume I \& II (G. Jefferson, Eed.). WileyBlackwell.

Scarlato, M., d'Agostino, G., \& Capparucci, F. (2016). Evaluating CCTs from a gender perspective: The impact of Chile Solidario on women's employment prospect. Journal of International Development, 28(2), 177-197. https://doi.org/10.1002/ jid.3124

Schegloff, E. A. (2007a). Sequence organisation in interaction: A primer in conversation analysis (Vol. 1). Cambridge University Press.

Schegloff, E. A. (2007b). A tutorial on membership categorisation. Journal of Pragmatics, 39(3), 462-482. https://doi.org/10.1016/j.pragma.2006.07.007

Stokoe, E. (2012). Categorial systematics. Discourse Studies, 14(3), 345-354. https://doi. org/10.1177/1461445612441543

World Bank. (2016). Ghana Social Protection Assessment and Public Expenditure Review. World Bank, Washington, DC. 


\section{Adapted Jeffersonian's transcription notation}

Symbol

$[[$

[text]

$=$

(.)

(number of seconds)

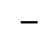

:

$\because::$

$\uparrow$

$\downarrow$

Underline

$\circ$

(( text )

( text)

( )

$>$ text $<$

$<$ text $>$

\{\}
Brief Description

: Utterances are simultaneously linked.

:The start and end of overlapping utterances.

: Latching utterances without noticeable pause.

: A micro pause of less than 0.2 seconds.

: A timed gap of utterance in tenths of a second.

: A short untimed pause within an utterance.

: An extension of a sound or syllable.

: A prolongation of an utterance.

: A rising shift in intonation.

: A falling shift in intonation.

: Emphasis on an utterance.

: An utterance quieter than surrounding talk. : A description of non-verbal activity.

: A transcriber's doubt of an utterance.

: A space mark of an indecipherable utterance.

: A more rapid utterance than surrounding talk.

: A slower utterance than surrounding talk.

: Codeswitching 